\title{
Relationship Between Blood Lead Level and Elevated Blood Pressure in Hypertensive Patients: Implication of Nitric Oxide
}

\author{
Abdel-Raheim M.A. Meki*,1, Abdullah A. Alghasham ${ }^{2}$ and Hisham A.S. Ismail ${ }^{3}$ \\ ${ }^{1}$ Departments of Biochemistry; ${ }^{2}$ Pharmacology and Therapeutics and ${ }^{3}$ Clinical Pathology, College of Medicine, Qassim \\ University, Qassim, Kingdom of Saudi Arabia (KSA)
}

\begin{abstract}
The correlation between the blood lead $(\mathrm{B}-\mathrm{Pb})$ levels and the values of blood pressure in hypertensive patients was investigated. Moreover, plasma levels of nitric oxide (NO), total antioxidants (TAOX) and malondialdehyde (MDA) were detected to investigate the correlations between the measured parameters and $\mathrm{B}-\mathrm{Pb}$ levels in hypertensive patients. Fifty-five hypertensive patients were compared with fifty-three age and sex matched control group. The B-Pb levels were detected by flame atomic absorption spectrometry. The plasma levels of NO, TAOX and MDA were measured by colorimetric methods. In the hypertensive patients, B-Pb levels were significantly higher than controls. Concomitantly, the plasma levels of MDA were significantly increased while the plasma levels of NO and TAOX were significantly reduced in the hypertensive patients in comparison with controls. There were significant positive correlations between $\mathrm{B}-\mathrm{Pb}$ and each of MDA, systolic and diastolic blood pressure. Conversely, a significant negative correlation was found between B$\mathrm{Pb}$ and $\mathrm{NO}$. Our study indicated that $\mathrm{B}-\mathrm{Pb}$ level was associated with elevated blood pressure as well as oxidative stress in hypertensive patients. Moreover, the negative correlation between the $\mathrm{B}-\mathrm{Pb}$ level and $\mathrm{NO}$ level may clarify their implication in cardiovascular disease and hypertension.
\end{abstract}

Keywords: Hypertension, B-Pb, NO, TAOX, MDA.

\section{INTRODUCTION}

Lead is a common environmental and industrial pollutant with no beneficial biological role. It has been detected in all phases of environment and biological system. The persistence of lead in the blood of animals and humans and the associated health risk is a topic of current debate and concern [1,2]. Moreover, rapid industrialization and the continued use of leaded gasoline appear to be increasing lead exposure throughout the developing world [3]. Considerable attention has been paid to the possibility that low levels of lead exposure among adults in the general population can elevate blood pressure and increase the risk for cardiovascular disease morbidity and mortality [4-7].

The notion that lead exposure may influence blood pressure in humans is biologically plausible. Hu et al., [8] reported significantly higher levels of lead in skeletal and blood compartments among men with hypertension. Previously, some investigators reported that lead induces hypertension in rats $[9,10]$. Other animal data suggested that lead acts at multiple sites within the cardiovascular system, including direct effects on the excitability and contractility of the heart, alteration of the compliance of the vascular smooth muscle tissue, and direct action on parts of the central nervous system responsible for blood pressure regulation [4]. Evidence in animals also suggested that lead may affect blood pressure through the renin- angiotensin system [9].

Many studies have provided new insights into the mechanisms by which metals can influence vascular

\footnotetext{
*Address correspondence to this author at the Qassim University, College of Medicine, Biochemistry Department., Kingdom of Saudi Arabia (KSA); Tel: (0)+9663800050; Ext: 2059; E-mail: Meki202000@Yahoo.com
}

function. Basal vascular tone impairment has been suggested as a possible mechanism of lead-induced hypertension. Thus, studies described by many investigators [11] suggested that low-concentration of lead exposure produced an imbalance of endothelial derived vasoconstrictor and vasodilator factors showed that the vasoconstrictor tone was conducive to hypertension. Moreover, the increased vasoconstriction was also accompanied by a rise in plasma levels of endothelin-3 and a decrease in plasma and urinary cyclic guanosine monophosphate [11]. Moreover, Sanchez-Mendoza et al., [12] have demonstrated that in hypertensive rats, decreased vasodilator tone is associated to increased vasoconstrictor response and that decreased NO production was responsible for this decreased vascular tone.

Oxidative stress is a condition of oxidant / antioxidant disequilibrium, in which increased reactive oxygen species (ROS) generation overwhelms antioxidant defence mechanisms leading to oxidative damage of cellular molecules. Of these, lipids are the most sensitive in that polyunsaturated fatty acids in cell membrane react with free radicals to form peroxidation products. Malondialdehyde (MDA) is the end product and best-known indicator of lipid peroxidation. To deal with harmful effects of ROS, a network of antioxidant defence mechanisms exist. Insufficient antioxidant protection or excess production of ROS can result in oxidative stress [13].

Farmand et al., [14] suggested that lead-induced hypertension is related to an over- production of ROS. ROS may increase blood pressure directly or indirectly by increasing the concentration of calcium in endothelial cells. The release of ROS increases the arterial blood pressure and induces atherosclerotic changes in blood vessels. In 
consequence, it may lead to arterial hypertension and coronary heart disease $[15,16]$.

Although the evidence in support of a role of leadinduced hypertension is strong, it is not conclusive, nor is the mechanisms by which lead may act on the vascular system clear. Lead exposure may be more of a risk factor for certain "susceptible populations", and thus may not be apparent in the general population. Inasmuch as hypertension remains a significant risk factor for other forms of cardiovascular disease, the propensity for environmental exposure actors to contribute to this risk is, potentially, an important public health concern [2].

According to this background, the current study was conducted to determine the blood lead (B-Pb) levels in hypertensive patients and to investigate the correlation between $\mathrm{B}-\mathrm{Pb}$ levels and the values of blood pressure in hypertensive patients. Moreover, the plasma levels of nitric oxide (NO), total antioxidants (TAOX) and malondialdehyde (MDA) were detected to investigate the correlations between these measured parameters and $\mathrm{B}-\mathrm{Pb}$ levels.

\section{MATERIALS AND METHODS}

In the present study, 55 consecutive hypertensive patients were recruited, during their routine check-up in the OPD clinic, Qassim University, College of Medicine, during January - March, 2010. After approval by the ethics committee of the College of Medicine, Qassim University, Saudia Arabia, an informed consent was obtained from each subject enrolled in the study. The patients were males and their ages ranged from 24 - 59 years. Fifty-three apparently healthy volunteer normotensive controls were matched hypertensive patients in age, sex and body mass index (BMI).

Each patient was subjected to full complete medical history including duration of the disease and details of therapy. Before inclusion, all participants underwent careful physical examination and detailed laboratory investigations to exclude any conditions that may interfere with the disease. Full clinical examination including fundus examination and routine investigations (ECG, ultrasonography, chest X-ray, and complete urine analysis). Also, the BMI (weight, $\mathrm{Kg} /(\text { height })^{2}, \mathrm{~m}^{2}$ ) was calculated. All patients were examined for any complications. Exclusion criteria included smoking, history of recent acute illness, clinical evidence suggestive of any liver or kidney diseases. We used the mean of three systolic and diastolic blood pressure measurements, all of which were taken by a physician in the Clinical Unit of Qassim University. Patients were categorized as hypertensive if any of the following criteria were met: current user of blood pressure medication (self-report), a systolic blood pressure of $140 \mathrm{~mm} \mathrm{Hg}$ or higher, or a diastolic blood pressure of $90 \mathrm{~mm} \mathrm{Hg}$ or higher [17].

Blood sample $(10 \mathrm{~mL})$ was collected in two heparinized tubes from each participant. The first tube was centrifuged at $5000 \mathrm{rpm}$ for $10 \mathrm{~min}$ for plasma separation. The plasma sample was divided into aliquots and kept at $-70^{\circ} \mathrm{C}$ until biochemical analyses. The second tube contained whole blood was used for $\mathrm{B}-\mathrm{Pb}$ determination. The lead levels in the blood were determined by employing flame atomic absorption spectrometry according to previously reported methods [18]. Calibration curve was constructed by adding known amounts of lead standard (E. Merck). Analysis of diluted samples of blood was injected into the atomic absorption spectrophotometer (Perkin-Elmer Model 400, Shelton, CT, USA). Hollow cathode lamp of $\mathrm{Pb}$ was used at wavelength of $283.3 \mathrm{~nm}$. The results of $\mathrm{B}-\mathrm{Pb}$ levels were expressed as $\mu \mathrm{g} / \mathrm{dl}$.

The plasma levels of TAOX capacity were determined according to Koracevic et al., [19] using commercial kit.The plasma level of MDA was determined using 1,1,3,3tetraehoxypropane as malondialdehyde standard and mixing equal volumes of the coloring reagent $(0.375 \%$ thiobarbituric acid, $\mathrm{w} / \mathrm{v}$, in $15 \%$ trichloroacetic acid $+0.25 \% \mathrm{~N} \mathrm{HCl})$ and samples or standards and $10 \mu \mathrm{L}$ of butylated hydroxyltoluene $\left(0.8, \mathrm{w} / \mathrm{v}\right.$, in hexane), incubated at $100{ }^{\circ} \mathrm{C}$ for $15 \mathrm{~min}$, cooled and centrifuged at $3000 \mathrm{rpm}$ for $10 \mathrm{~min}$. MDA and thiobarbituric acid react to form a pink color. Absorbance at $535 \mathrm{~nm}$ of the supernatant was recorded against reagent blank and concentration in $\mu \mathrm{M}$ was calculated from standard curve $(0.25-20 \mu \mathrm{M})$ [20]. The plasma levels of NO was determined as total nitrite after deproteinzation with $\mathrm{ZnSO}_{4}$ $(30 \%)$, nitrate reduction with cadmium (activated by $2 \%$ $\mathrm{HcL}$ ) and the color developed by the reaction with Griess reagent $(1 \%$ sulfanilamide/ $0.1 \%$ naphthyelthylene diamine $\mathrm{diHCL}, \mathrm{w} / \mathrm{v}$ in $2.5 \% \mathrm{H}_{3} \mathrm{PO}_{4}$ ) was recorded at $550 \mathrm{~nm}$ against reagent blank using sodium nitrite $10-100 \mu \mathrm{M}$ as standard [21].

\section{Statistical Analysis}

The statistical analysis was performed using Prism Statistical Package version 5.0 (Graphpad, San Diego, CA, USA). Data comparisons were performed by using student $t$ test and ANOVA with Bonferroni's post multiple comparisons test and the correlations among the clinical and biochemical parameters were performed using Spearman's rank correlation coefficient. The levels of significance were accepted with $\mathrm{P}<0.05$ and the results were presented in Tables as mean \pm SEM.

\section{RESULTS}

The clinical criteria of patients and controls are summarized in Tables 1. Age and BMI did not show significant differences among the comparable groups. The B$\mathrm{Pb}$ levels and the plasma levels of bioindices in hypertensive patients comparing with controls were shown in Table $\mathbf{2}$. The $\mathrm{B}-\mathrm{Pb}$ levels were significantly higher in hypertensive patients than controls. The plasma levels of MDA were significantly increased in the hypertensive patients in comparison with controls. Unlikely, the plasma levels of NO and TAOX were significantly lower in hypertensive patients than control group. The correlations between the B-Pb levels and clinical and biochemical indices in hypertensive patients were shown in Table 3. There were significant positive correlations between $\mathrm{B}-\mathrm{Pb}$ and each of MDA, systolic and diastolic blood pressure. Conversely, a significant negative correlation was found between $\mathrm{B}-\mathrm{Pb}$ and NO. No significant correlations were found between the $\mathrm{B}-\mathrm{Pb}$ levels and each of age, TAOX, and BMI in hypertensive patients.

\section{DISCUSSION}

There is considerable public health interest in the possible toxic effects of environmental lead exposure on the cardiovascular system, with additional concern regarding the 
Table 1. Clinical Characteristics in Hypertensive Patients Compared with Controls

\begin{tabular}{|c|c|c|c|}
\hline Parameters & $\begin{array}{c}\text { Controls } \\
(n=53)\end{array}$ & $\begin{array}{l}\text { Hypertensive Patients } \\
\qquad(\mathrm{n}=55)\end{array}$ & P-Value \\
\hline Age (years) & $39.92 \pm 1.209$ & $43.16 \pm 1.292$ & $\mathrm{P}<0.07 \mathrm{NS}$ \\
\hline BMI $\left(\mathrm{kg} / \mathrm{m}^{2}\right)$ & $28.53 \pm 0.541$ & $29.87 \pm 0.509$ & $\begin{array}{c}\mathrm{P}<0.07 \\
\mathrm{NS}\end{array}$ \\
\hline $\begin{array}{c}\text { Blood pressure } \\
\text { Systolic }(\mathrm{mmHg}) \\
\text { Diastolic }(\mathrm{mmHg})\end{array}$ & $\begin{array}{c}114.30 \pm 0.831 \\
80.26 \pm 0.505\end{array}$ & $\begin{array}{c}137.60 \pm 2.045 \\
90.29 \pm 1.063\end{array}$ & $\begin{array}{l}\mathrm{P}<0.0001 \\
\mathrm{P}<0.0001\end{array}$ \\
\hline
\end{tabular}

Results are expressed as mean \pm SE; BMI, Body mass index, NS, non significant.

Table 2. Blood Lead and Plasma Levels of Bio-Indices in Hypertensive Patients Compared with Controls

\begin{tabular}{|c|c|c|c|}
\hline Parameters & $\begin{array}{c}\text { Controls } \\
(\mathbf{n = 5 3 )}\end{array}$ & $\begin{array}{c}\text { Hypertensive Patients } \\
(\mathbf{n}=\mathbf{5 5})\end{array}$ & P-Value \\
\hline \hline $\mathrm{B}-\mathrm{Pb}(\mu \mathrm{g} / \mathrm{dL})$ & $1.85 \pm 0.132$ & $2.21 \pm 0.125$ & $\mathrm{P}<0.05$ \\
\hline $\mathrm{NO}(\mathrm{nmol} / \mathrm{ml})$ & $27.87 \pm 2.443$ & $18.67 \pm 0.923$ & $\mathrm{P}<0.001$ \\
$\mathrm{ACE}(\mathrm{U} / \mathrm{L})$ & $1.189 \pm 0.017$ & $1.073 \pm 0.036$ & $\mathrm{P}<0.01$ \\
\hline $\mathrm{TAOX}(\mathrm{mmol} / \mathrm{L})$ & $1.74 \pm 0.036$ & $2.16 \pm 0.049$ & $\mathrm{P}<0.001$ \\
\hline $\mathrm{MDA}(\mu \mathrm{mol} / \mathrm{L})$ & & & \\
\hline
\end{tabular}

Results are expressed as mean \pm SE; B-Pb, blood lead; NO, nitric oxide; TAOX, total antioxidant capacity; MDA, malodialdehyde.

Table 3. Correlations of B-Pb Levels with Age, BMI, Systolic BP, Diastolic BP, NO, ACE, TAOX and MDA in Hypertensive Patient

\begin{tabular}{|c|c|c|}
\hline Variables & $\begin{array}{c}\text { Correlation Coefficient } \\
\text { (r) }\end{array}$ & P-Value \\
\hline $\mathrm{B}-\mathrm{Pb}$ vs & & \\
\hline NO & -0.46 & $\mathrm{P}<0.01 *$ \\
\hline TAOX & -0.30 & NS \\
\hline MDA & +0.51 & $\mathrm{P}<0.05^{*}$ \\
\hline Systolic BP & +0.41 & $\mathrm{P}<0.01 *$ \\
\hline Diastolic BP & +0.39 & $\mathrm{P}<0.05 *$ \\
\hline BMI & +0.12 & NS \\
\hline
\end{tabular}

*significant; B-Pb, blood lead; BP, blood pressure; NO, nitric oxide; TAOX, total antioxidant capacity; MDA, malodialdehyde; BMI, body mass index; NS, non significant.

role of chronic low-level lead exposures in the pathogenesis of hypertension, a leading risk factor for cardiovascular disease morbidity and mortality [7, 2]. Vupputuri et al., [22] suggested that increased levels of $\mathrm{B}-\mathrm{Pb}$ remain an important environmental risk factor for elevated blood pressure. Many studies [23, 24] but not all [25] have indicated that environmental exposure to lead is associated with an increased risk of hypertension. Martin et al., [26] suggested that lead has an acute effect on blood pressure via recent dose and a chronic effect on hypertension risk via cumulative dose.

In the present study, the $\mathrm{B}-\mathrm{Pb}$ levels were significantly higher in hypertensive patients than controls and positively correlated with the increase of systolic and diastolic blood pressure level. In this regard, Dursun et al., [27] found a significant elevation of the mean systolic and diastolic blood pressures in the lead-treated rats when compared to healthy controls. Robles et al., [28] confirmed the hypertensive effect of lead exposure. Vupputuri et al., [22] showed that significant associations between blood lead level and systolic and diastolic blood pressures in black men. Nash et al., [17] found that $\mathrm{B}-\mathrm{Pb}$ level is positively associated with both systolic and diastolic blood pressure in postmenopausal women. Recently, Kasperczyk et al., [29] found that B-Pb levels were positively correlated with high arterial blood pressure (both systolic and diastolic). Moreover, Afridi et al., [30] reported higher levels of $\mathrm{B}-\mathrm{Pb}$ as well as a lower level of $\mathrm{Zn}$, correlated well with the consequences of 
hypertension. Conversely, Staessen et al., [31] failed to recognize a significant relation between $\mathrm{B}-\mathrm{Pb}$ and hypertension.

Age and BMI are very strong factors that induces hypertension but they seem to be independent of lead effect. Kasperczyk et al., [29] did not find a correlation between B$\mathrm{Pb}$ and $\mathrm{BMI}$ or age. Our study showed similar finding. Unlikely, Harlan, [23] found that BMI has an inverse relation to $\mathrm{B}-\mathrm{Pb}$ in the US population. deQueiroz et al., [32] found that BMI is significantly correlated with the increase in blood pressure levels.

There are many reports in the literature proposing possible physiological and cellular mechanisms of lead induced hypertension based on animal and in vitro studies. Lead may cause enhanced sympathetic nerve activity with increases in circulating epinephrine and norepinephrine levels in conjunction with decreased density of vasodilating beta 2 adrenergic receptors [33]. Chronic low-level exposure to lead results in increased activity of angiotensin converting enzyme activity and increases in plasma renin, angiotensin II, and aldosterone levels [34]. Plasma kininase I and II levels are higher during $\mathrm{Pb}$ exposure.This can lead to decreases in plasma bradykinin levels resulting in a reduction in endothelial NO production [35].

There is very strong evidence that lead decreases the functional availability of the potent vasodilator NO, most likely through direct or indirect mechanisms involving oxidative stress [34]. In the current study, the plasma levels of NO were significantly lower in hypertensive patients than controls. The $\mathrm{B}-\mathrm{Pb}$ levels were negatively correlated with NO levels in hypertensive patients. In this regard, Dursun et al., [27] showed that exposure to low lead results in a marked decrease of plasma NO levels. Robles et al., [28] suggested that decreased NO synthesis or increased NO catabolism are present in the hypertensive animals. ROS are logical candidates to mediate NO modulation; moreover, Robles et al., [28] demonstrated that lead treatment was associated with increased ROS production and inactivation of NO. Thus, high ROS levels after lead-exposure may increase the presence of superoxide anion, raising the probabilities of an interaction between $\mathrm{NO}$ and ROS to produce a peroxynitrite, highly deleterious molecule.

Peroxynitrite is a strong, relatively long-lived oxidant which has been implicated in tissue injury. It is known to initiate lipid peroxidation and might lead to irreversible tissue damage, and impaired vascular function [36]. Robles et al., [28] suggested that NO production or release is impaired as a result of lead-exposure. Taken together, the data suggest that upon lead exposure, a higher production of ROS is generated, inactivating NO.

Many reports have suggested that lead-induced hypertension is related to an over production of free radicals and/or a decrease of the antioxidative mechanisms in the body [14,37]. The release of ROS increases the arterial blood pressure and induces atherosclerotic changes in blood vessels. In consequence, it may lead to arterial hypertension and coronary heart disease $[15,16]$.

In the current study, plasma levels of TAOX were significantly lower but plasma levels of MDA were significantly higher in hypertensive patients than controls.
The $\mathrm{B}-\mathrm{Pb}$ concentrations were positively correlated with MDA levels in hypertensive patients. In this regard, many studies $[38,39]$ have proven that the exposure of human to lead compounds results in increased peroxidation of lipids in blood, due to changes in the activity of antioxidant enzymes. Moreover, Kasperczyk et al., [29] found a positive correlation between $\mathrm{B}-\mathrm{Pb}$ and MDA among human exposed to lead. Conversely, Dursun et al., [27] showed that lead administration results in hypertension and a nonsignificant rise in plasma concentration of lipid peroxides.

Previous reports have shown that lead-induced hypertension could be related to an increase in $\operatorname{ROS}[15,16]$. In addition, it is widely accepted that oxidative stress may contribute to the generation of hypertension and endothelial dysfunction via the inactivation of NO [35]. Robles et al., [28] demonstrated that rats exposed to lead had a higher production of ROS, such that coadministration of lead with antioxidant treatment was able to prevent the oxidative stress and the hypertensive effect of lead treatment.

\section{CONCLUSION}

The blood lead level is significantly and positively correlated with blood pressure among hypertensive patients. Lead exposure may increase blood pressure through increase the oxidative stress and NO reduction. Further biochemical and epidemiological researches are needed, especially in the field of metal exposure -induced hypertension, to determine the pathological; clinical significances and the mechanisms of the adverse effects as well as to support our findings and to study their direct impact on cardiovascular outcomes.

\section{ACKNOWLEDGEMENTS}

The study was supported by a grant number SR-S-00908, from the sabic, Qassim University, Saudi Arabia. I am grateful to our lab specialist Mr. Bandar Talhi for helping in the lab.

\section{REFERENCES}

[1] Juberg, D.R.; Kleiman C.F.; Simona, C.K. Position paper of the American Council on Science and Health: lead and human health. Ecotoxicol. Environ. Saf., 1997, 38, 162-180.

[2] Prozialeck, W.C.; Edwards, J.R.; Nebert, D.W.; Woods, J.M.; Barchowsky, A.; Atchison, W.D. The vascular system as a target of metal toxicity. Toxicol. Sci., 2008, 102 (2), 207-218.

[3] Wu, W.T.; Tsai, P.J.; Yang, Y.H.; Yang, C.Y.; Cheng, K.F.; Wu, T.N. Health impacts associated with the implementation of a national petrol-lead phase-out program (PLPOP): Evidence from Taiwan between 1981 and 2007. Sci. Total Environ., 2011, 409 (5), 863-867.

[4] Kopp, S.J.; Barron, J.T.; Tow, J.P. Cardiovascular actions of lead and relationship to hypertension: a review. Environ Health Perspect. 1988, 78, 91-99.

[5] Burt, V.L., Whelton, P., Roccella, E.J., Brown, C.; Cutler, J.A., Higgins, M., Horan, M.J.; Labarthe, D. Prevalence of the Third National Health and Nutrition Examination Survey, 19881991. Hypertension, 1995, 25, 305-313.

[6] Ibrahim, D., Froberg, B., Wolf, A., Rusyniak, D.E. Heavy metal poisoning: Clinical presentations and pathophysiology. Clin. Lab. Med., 2006, 26, 67-97.

[7] Hertz-Picciotto, I.; Croft, J. Review of the relation between blood lead and blood pressure. Epidemiol. Rev., 1993, 15, 352-373.

[8] Hu, H.; Aro, A.; Payton, M.; Korrick, S.; Sparrow, D., Weiss, S.T.; Rotnitzky, A. The relationship of bone and blood lead to hypertension: the Normative Aging Study. JAMA, 1996, 275, 11711176.

[9] Vander, A.J. Chronic effects of lead on the renin angiotensin system. Environ. Health Perspect., 1988, 78, 77-83. 
[10] Nowack, R.; Wiecek A.; Exner B.; Gretz N.; Ritz E. Chronic lead exposure in rats: effects on blood pressure. Eur. J. Clin. Invest., 1993, 23, 433-443.

[11] Khalil-Manesh, F.; Gonick, H.C.; Weiler, E.W.; Prins B.; Weber, M. A.; Purdy, R.E. Lead-induced hypertension: Possible role of endothelial factors. Am. J. Hypertens., 1993, 6, 723-729.

[12] Sanchez-Mendoza, A.; Hong, E.; Escalante, B. The role of nitric oxide in angiotensin II-induced renal asoconstriction in renovascular hipertension. J. Hypertens., 1998, 16, 697-703.

[13] Urso, C.; Caimi G. Oxidative stress and endothelial dysfunction. Minerva Med., 2011, 102 (1), 59-77.

[14] Farmand, F.; Ehdaie, A.; Roberts, C.H.K.; Sindhu, R.K. Leadinduced dysregulation of superoxide dismutases, catalase, glutathione peroxidase, and guanylate cyclase. Environ. Res., 2005, 98, 33-39.

[15] Gonick, H.C.; Ding, Y.; Bondy, S.C.; Ni, Z.; Vaziri, N.D. Leadinduced hypertension interplay of nitric oxide and reactive oxygen species. Hypertension, 1997, 30, 1487-92.

[16] Vaziri, N.D.; Khan, M. Interplay of reactive oxygen species and nitric oxide in the pathogenesis of experimental lead-induced hypertension. Clin. Exp. Pharmacol. Physiol., 2007, 34 (9), 920-5.

[17] Nash, D.; Magder, L.; Lustberg, M.; Sherwin, R.W.; Rubin, R.J.; Kaufmann, R.B.; Silbergeld, E.K. Blood lead, blood pressure, and hypertension in perimenopausal and postmenopausal women. JAMA, 2003, 289 (12), 1523-1532.

[18] Villeda-Hernandez, J.; Barroso-Moguel, R.; Mendez-Armenta, M.; Nava-Ruız, C. Huerta-Romero, R. Enhanced brain regional lipid peroxidation in developing rats exposed to low level lead acetate. Brain Res. Bull., 2001, 55 (2), 247-251.

[19] Koracevic, D.; Koracevic, G.; Djordjevic, V.; Andrejevic, S.; Cosic, V. Method for the measurement of antioxidant activity in human fluids. J. Clin. Pathol., 2001, 54 (5), 356-361.

[20] Beuge, J.A.; Aust, S.D.Microsomal lipid peroxidation. Method. Enzymol., 1978; 52, 302-10.

[21] Ding, A.H.; Nathan, C.F.; Stuchr, D.J. Release of reactive nitrogen intermediates and reactive oxygen intermediate from mouse peritoneal macrophages. Comparison of activating cytokines and evidence for independent production. J. Immun., 1988, 141, 24072412.

[22] Vupputuri, S., He J., Muntner, P., Bazzano, L.A., Whelton, P.K., Batuman, V. Blood lead level is associated with elevated blood pressure in blacks. Hypertension. 2003, 41 (3), 463-468.

[23] Harlan, W.R. The relationship of blood lead levels to blood pressure in the U.S. population. Environ. Health Perspect., 1988, 78, 9-13.

[24] Cheng, Y.; Schwartz, J.; Sparrow, D.; Aro, A.; Weiss, S.T.; Hu, H. Bone lead and blood lead levels in relation to baseline blood pressure and the prospective development of hypertension: the Normative Aging Study. Am. J. Epidemiol., 2001, 153, 164-171.

[25] Chu, N.F.; Liou, S.H.; Wu, T.N.; Chang, P.Y. Reappraisal of the relation between blood lead concentration and blood pressure among the general population in Taiwan. Occup. Environ. Med., 1999, 56, 30-33.
[26] Martin, D.; Glass, T.A.; Bandeen-Roche, K.; Todd, A.C.; Shi, W.; Schwartz, B.S. Association of blood lead and tibia lead with blood pressure and hypertension in a community sample of older adults. Am. J. Epidemiol., 2006, 163 (5), 467-478.

[27] Dursun N., Arifoglu C., Süer C., Keskinol L. Blood pressure relationship to nitric oxide, lipid peroxidation, renal function, and renal blood flow in rats exposed to low lead levels. Biol. Trace. Elem. Res., 2005, 104 (2), 141-9.

[28] Robles, H.V.; Romo, E.; Sanchez-Mendoza, A.; Rios, A.; Soto V.; Avila-Casado, M. C.; Medina, A.; Escalante, B. Lead exposure effect on angiotensin II renal vasoconstriction. Hum. Exp. Toxicol., 2007, 26, 499-507

[29] Kasperczyk, S.; Kasperczyk, J.; Ostałowska, A., Zalejska-Fiolka, J.; Wielkoszyński ,T.; Swietochowska, E.; Birkner, E. The role of the antioxidant enzymes in erythrocytes in the development of arterial hypertension among humans exposed to lead. Biol. Trace Elem. Res., 2009, 130 (2), 95-106.

[30] Afridi, H.I.; Kazi, T.G.; Kazi, N.G.; Jamali, M.K.; Arain, M.B.; Sirajuddin, Baig J.A.; Kandhro, G.A.; Wadhwa, S.K.; Shah, A.Q. Evaluation of cadmium, lead, nickel and zinc status in biological samples of smokers and nonsmokers hypertensive patients. J. Hum. Hypertens., 2010, 24 (1), 34-43.

[31] Staessen, J.A.; Lauwerys, R.R.; Buchet, J.P.; Bulpitt, C.J.; Rondia, D.; Vanrenterghem, Y.; Amery, A. Impairment of renal function with increasing blood lead concentrations in the general population: the Cadmibel Study Group. N. Engl. J. Med., 1992, 327, 151-156.

[32] de Queiroz, V.M.; Moreira, P.V.; de Vasconcelos, T.H.; de Toledo Vianna, R.P. Prevalence and anthropometric predictors of high blood pressure in schoolchildren from João Pessoa - PB, Brazil. Arq. Bras. Cardiol., 2010, 95 (5), 629-634.

[33] Tsao, D.A.; Yu, H.S.; Cheng, J.T.; Ho, C.K.; Chang, H.R.The change of beta adrenergic system in lead-induced hypertension. Toxicol. Appl. Pharmacol., 2000, 164, 127-133.

[34] Vaziri, N.D. Pathogenesis of lead-induced hypertension: Role of oxidative stress. J. Hypertens. Suppl., 2002 , 20 (3), S15-S20.

[35] Carmignani, M.; Boscolo, P.; Poma, A.; Volpe, A. R. Kininergic system and arterial hypertension following chronic exposure to inorganic lead. Immunopharmacology, 1999, 44, 105-110.

[36] Villa, L.M.; Salas, E.; Darley-usmar, V.M.; Radomski, M.W.; Moncada S. Peroxynitrite induces both vasodilation and impaired vascular relaxation in the isolated perfused heratproc. Proc. Natl. Acad. Sci. USA, 1994, 91, 12383-12387.

[37] Vaziri, N. D.; Liang, K.; Ding, Y. Increased nitric oxide inactivation by reactive oxygen species in lead-induced hypertension. Kidney Int., 1999, 56, 1492-1498.

[38] Kasperczyk, S.; Birkner, E.; Kasperczyk, A.; Kasperczyk, J. Lipids, lipid peroxidation and 7-ketocholesterol in workers exposed to lead. Hum. Exp. Toxicol., 2005, 24 (6), 287-95.

[39] Kasperczyk, S.; Birkner, E.; Kasperczyk, A.; Zalejska-Fiolka, J. Activity of superoxide dismutase and catalase in people protractedly exposed to lead compounds. Ann. Agric. Environ. Med., 2004, 11 (2), 291-296. 